\title{
Education for Consumer Citizenship in Greece: Teaching Student Teachers and High School Students
}

\author{
Koutrouba Konstantina, Theodoropoulou Helen, Barda Constantia \\ Harokopio University of Athens, Athens, Greece
}

\begin{abstract}
In the frame of the Greek educational system, education for consumer citizenship is provided to thirteen-year-old students who attend courses on home economics in junior high school. Students' training is focused, among others, on their acquaintance with the notion and the basic principles of consumption, primarily within the frame of family running, and, secondly, in the frame of narrower or broader social settings. Students are consequently expected to actively develop styles of mature consuming behaviour in family, school, and society. In the Faculty of Home Economics and Ecology at Harokopio University of Athens, student teachers attend special courses on consumer citizenship are systematically trained to use effectively alternative instructional strategies during the teaching of subject units that refer to consumer citizenship. The present study aims at presenting, firstly, how Greek student teachers are trained through University Syllabus and Practicum in order to be qualified as educators for consumer citizenship, and, secondly, how they diffuse this specific knowledge to their students during their years of in-class service. In addition, the study examines the career satisfaction of the graduates of home economics and ecology at Harokopio University of Athens. The result of the present study showed that the great majority of graduates were promptly appointed as teachers to Greek high schools, and today they are considered to play a major role in the conveyance of the education for consumer citizenship's principles in Greek society, since home economics is the only junior high school subject that promotes and develops consumer awareness in Greek secondary education.
\end{abstract}

Keywords: consumer citizenship, education, training, instructional strategies, consumer awareness

\section{Introduction}

As it usually happens with most complex social phenomena which need to be brought under consideration within the framework of education in order to be faced effectively by present students and future citizens, consumerism increasingly tends to be considered by educational systems as a problem which is per se insurmountable, given the fact that material goods' abundance and consumption are supposed to be an only and definitely irrevocable way to individual welfare and consequent global development through the strengthening of

Koutrouba Konstantina, Ph.D., Assistant Professor, Department of Home Economics and Ecology, Harokopio University of Athens.

Theodoropoulou Helen, M.S., Ph.D., Associate Professor, Department of Home Economics and Ecology, Harokopio University of Athens.

Barda Constantia, M.S., Ph.D. candidate, Department of Home Economics and Ecology, Harokopio University of Athens.

Correspondence concerning this article should be addressed to Theodoropoulou Helen, Department of Home Economics and Ecology, Harokopio University of Athens, 70 E. Venizelou, 17671 Athens, Greece. E-mail: etheodo@hua.gr. 
economic growth (Davis \& Sumara, 2006). It is, therefore, much easier for contemporary educational systems around the world, which somehow or other protect social dogmas and convey society's fundamental values to younger members, to accept consumption's superpower and to deal merely with consequences and impacts of consumerism by highlighting the responsibility of present consumers' decisions and behaviors for the future generations, than to challenge modern society's orientations and, if possible, to refute an almost solidified fallacious creed that human happiness is unbreakably connected with excessive, or in some cases even with rational consumption (Doyle, 2006). It is obvious, however, that the more financially developed the country is, the more difficult for its educational system is to serve a sincere anti-consumerism ideology, especially in cases where the education is expected at the same time, but rather to the opposite direction, to boost a rapid technological growth and mould characters who, in the future, will participate more actively, effectively, restlessly in the process of production, and inevitably, after that, in the process of consumption (McGregor, 2008). Humanistic ideals, of course, are not absent from the objectives of most western countries' educational systems, repeatedly, however, the outcomes of educational processes are evaluated in terms of quantity, not of quality. Financially developed societies provide to their students/citizens more schools, wider education, broader knowledge, numerous opportunities for participation in cultural creation, even a wide, rich range of socially proposed features (adaptability, effectiveness, self-development, self-realization, solidarity and so forth) from which a young person is expected to choose the ones she/he wants to adopt and develop in order to be more flexible, more adapted to the requirements of an excessively materialistic and minimally humanistic society. In other words, most educational systems adapt people to the needs of a commercial society instead of questioning the very orientation of such a society and struggle for a meaningful change (Peters, Britton, \& Blee, 2008).

Conversely, for a country such as Greece that is not yet fully developed in terms of economy, a very persistent humanistic orientation can be detected throughout its educational framework, despite the fact that free market economy's rules and values tend to be dominant after the Greece's participation as a full member in the European Economic and Monetary Union (2002) (Gamble, 2006). Motivated probably by its humanistic past, the education in Greece, especially primary and secondary, still lays stress on the students' development of qualitative features without, however, putting analogous emphasis on the contribution of this development to the future growth of country's economical welfare and affluence. Creating physically, cognitively and emotionally balanced personalities remains, to a certain extent, a main objective, while social sensitization and solidarity are expected to be developed through students' multifaceted contact with texts rich in authentic humanistic values, and socio-educational activities related to modern and ancient culture and tradition. The majority of school subjects do not only aim at promoting humanistic ideals, but also at revealing the impact of several negative modern phenomena. In such a framework, phenomena like consumerism in the form of agonized massive accumulation of goods and services are stigmatized through sporadic mentions incorporated in school subjects such as Greek literature and culture, history, citizenship education, religion issues, sociology and philosophy. An aggregate and thorough-going review, however, of consumerism is realized in Greek classrooms during the teaching of consumer citizenship, which is the pivotal core of modern home economics, an interdisciplinary school subject attended by thirteen-year-old students and constructed on the basis of cross-thematic school curricula's principles and experiential learning's objectives and instructional methods (Georgitsoyanni, Koutrouba, \& Goussia-Rizou, 2003). 
The aim of the present study was to present, firstly, how Greek student teachers are trained through University Syllabus and Practicum in order to be qualified as educators for consumer citizenship, and secondly, how they diffuse this specific knowledge to their students during their years of in-class service. In addition, the study examines the career satisfaction of the graduates of home economics and ecology at Harokopio University of Athens.

\section{How Greek Student Teachers Are Trained in Order to be Qualified as Educators for Consumer Citizenship}

Since home economics is the main junior high school subject that methodically promotes and systematically develops consumer awareness in Greek secondary education, the education and training of home economics' teachers is considered by the Greek state as a matter of prime importance. In the faculty of home economics and ecology at Harokopio University of Athens, student teachers attend special courses on consumer citizenship and sustainable development and are scientifically trained to use effectively alternative instructional strategies during the teaching of subject units that refer to relevant issues. Given the fact that, since 1998, when the first teachers completed their studies in the new autonomous university, all graduates have been promptly appointed as teachers to Greek high schools, today they are considered to play a major role in the conveyance of the education for consumer citizenship's principles in Greek society.

Student teachers at home economics university are educated to regard over-consumption primarily as a matter of ethics and secondarily as an economical issue. An obvious objective of such a perspective is Greek education's intention to reveal the intimate motives hidden behind consumerism and, therefore, to help students strike at the root of the problem instead of fighting against its consequences. Students probing deep into the mechanism of ancient Greece's socio-financial and political function and development, realize that over-consumption was considered as an index of the city-state's prosperity. From an archaic Doric ideal of self-restraint, abstinence and frugality in the eighth century B.C., Greeks moved gradually through the centuries to an almost overweening stance against simplicity in the early third century B.C.. Kings, tyrants and even democratic political leaders and orators tried to attribute their city's advancements and political dominion over the Mediterranean and Minor Asia world to the Greek affluence of goods, not only of material but also of cultural ones (Pomeroy, Burstein, Donlan, \& Roberts, 2008). Colonies and conquered regions, triremes, soldiers, slaves, friends, allies, provisions, theatres, stadiums and temples, feasts and symposia, works of intellect, political and philosophical speeches were estimated in terms of quantity, and as an evidence for luxury and affluence, despite the fact that only few prudent thinkers were concentrated on the pursuit of happiness through the seeking of quality (Koutrouba \& Apostolopoulos, 2003). The richer and more consumerist the ancient Greek citizens were becoming, the faster their transition from self-sufficiency to greed and loss of all sense of proportion was progressing. From an ethical point of view, modern Greek students can discern an apparent distortion of values, and their ancestors in the course of time started valuing "having" more than "being", turning consequently to an unleashed expansionist policy and despotic attitude towards others. Greek states' decline, as a result of a luxurious life and insatiable wish for more goods and amenities, provides modern students with a clear understanding of consumerism's deeper origin and consequences. Looking back into history Greek student teachers also review Byzantine Empire's decline after a long period of one thousand years of powerful domination over the medieval world, that came as a result of spiritual values' 
fading due to society's turn to seductive materialism.

A thorough research of consumerist phenomena is completed for Greek student teachers with an extensive examination of industrial revolution in the late eighteenth century and its contribution to the shaping of modern consumerist society. Students pore over the consequences of goods' massive production and consequent natural resources' exhaustion, as they are historically linked to the great powers' conflicts and wars and to the people's destructive steps to over-consumerism that alienated them from the humanitarian principles and values that Renaissance and the Age of Enlightenment had proposed and developed in the past centuries (Sassatelli, 2007).

This historical review on values, however, does not really aim at strengthening student teachers' cognitive background on history. It is rather used as a means of clear examination and explanation of a phenomenon and a feature that is so compactly connected to the very nature of modern man that any effort to detach it from modern man's personality looks rather futile (Hanashiro \& Malroutu, 2008). Yet, the planners of home economics' curricula, by familiarizing student teachers with the roots and the developing and changing forms of a very complicated socio-economical, but primarily ethical problem, which can be historically examined "in vitro", tend to believe that for a society that reconsiders its values and orientations, a rational blunting of this problem is not unfeasible.

\section{How Greek Teachers Diffuse Their Knowledge About Consumer Citizenship to Their Students}

Teachers of home economics, having themselves realized the ways that affluence allures and, in the long run, captivates and enslaves the conscience of a society that over-consumes, prompt their students, firstly, to get familiarized with the contemporary mechanisms that promote the ideology of consumption and, secondly, to develop personal strategies of resistance by reacting consciously and effectively within their narrow or broader social settings.

Discerning and separating fictitious from real needs constitutes the first step in developing a deeper understanding of over-consumption phenomenon. Teachers utilize the main principles of experiential learning, since students' everyday experience can be effectively used in order for their awareness to be stimulated and developed (Carroll \& Reichelt, 2008). Students, working in small groups, are prompted, on a daily basis and for a period exceeding one month, to draw up lists where all emerging needs are recorded. Every need is examined in connection with a defined social frame and, at the same time, with a distinct domain of human nature (physical, affective). Buying, for instance, a nice blouse fulfils primarily a physical need, but, simultaneously, the name of blouse's firm reflects the social stratum where the buyer belongs to. A consequent affective need is therefore satisfied, and by showing off our belongings we affirm our place in this particular stratum, strengthening thus our self-esteem and confidence (Williams, 2002). Students are expected to realize that affective need is not prime or imposed by nature. It actually follows a social need that, despite its importance, can be reconsidered and belittled with minimal consequences, on condition that one earnestly wants to take control of one's behaviour. Family income or other differentiating factors, such as gender, profession or level of education can affect the final choices of the consumer, but the over-consumption's core objective (affective relief within a highly demanding social environment) seems to be common for the majority of human beings (Frank \& Enkawa, 2009). A classification of needs reveals how many secondary requirements and corresponding products have been 
invented in order to fill a life vacuous in terms of meaningful and substantial values, in deed regardless the social stratum and the economic power of the consumer. During consumer citizenship education of the Greek students, the main interest focuses, therefore, not on what or, even, how much one finally buys and consumes, but rather on the values one embraces during consumption and on the objectives one pursues. If education manages to prove the insufficiency, superficiality and vanity of current material objectives, and to propose different ones (such as self-restraint, self-knowledge, balanced social interaction, solidarity and so forth) that can be attained with more spiritual ways and means (cultivation and fostering of humanitarian ideals, strengthening of social virtues and unity through education), then the problem is expected to have been struck at the very root of it. Students are prompted to construct simple questionnaires or to review members of their family environment in order to record their consuming objectives and values as well as the degree of satisfaction they experience due to consumption. Afterwards, under teachers' supervision and assistance, they elaborate the data collected, and draw their conclusions focusing mainly on the similarities of fundamental human objectives (fulfillment of physiological, safety, belonging, self-esteem and self-actualization needs, as they have been formulated by A. Maslow), which however are satisfied through the consumption of different products. Students collaboratively produce written essays where, after a guided research on social history and thought, they examine whether these main objectives can be fulfilled in different, less consumerist ways. Their conclusions and proposals are then communicated to all participants and fellow-citizens during school's interaction with local society.

The second step for students is their familiarization with the techniques of advertisement and goods' promotion. Students are prompted to collect, over a period of two months, different types of advertisements, to decode obvious or hidden messages, to analyze the means used, to define the consumers' target group, and to realize the new values founded, namely to realize that, despite the fact that projected values (such as beauty, happiness, success, acceptance) are already known to the target group, their linking to and dependence on the use of a particular material product produce a new kind of value without idealistic, theoretical or ethical connotations, a "value" that can be easily reached and obtained through marketplace procedures as it happens with all other material products (Carey, Shaw, \& Shiu, 2008). Students also analyze the background or complementary life and behaviour models projected by advertisements. Expensive houses, cars, jewels, modern conveniences, ambitious executives, desirable women, smartly-dressed and successfully raised children, sincere reciprocal feelings, all achieved and accomplished through the acquisition of goods, all picturing to consumer's imagination a model of sought after life and, even worse, a model of being. Students are prompted to download advertisements from commercial websites, to collect television, magazine and newspapers' advertisements, where different messages and models of thinking and feeling are expressed. They especially examine (during an interdisciplinary approach through language and literature, religion, history and social studies) the powerful attraction of language and picture, the ways that symbols are used and feelings are manipulated, and finally, the means used in order for the market's intentions and rules to dominate over consumer's will and consciousness. Roundtable and panel discussions, debates and role playing are actively used as a means for students to fully develop a personal stance against over-consumption. Moreover, in many cases, students, encouraged by their home economics' teacher, come in contact with national and international non-profit organizations for the protection of consumers' rights, they are informed, among others, about their rights against misleading advertisement and participate in short-range campaigns for the information of local community. 
In a third step of profound awareness students scrutinize consumerism's consequences firstly on human personality and secondly on natural resources and environment. As far as human personality is concerned, students examine how consumerist objectives alter one's behaviour in daily life. Consumers are convinced that, if they are to be free and avoid falling short of personal, family and social environment's expectations, they must satisfy their endlessly growing needs, by working longer and harder, by possessing and spending more, by adjusting and subjugating, in fact, his/her personal aspirations (physical, psychological, affective, social) to the illogical demands and for the benefit of a highly seductive, but virtually impersonal industry that eventually can enslave any unsuspecting consumer. Moreover, as far as consequences for natural resources and environment are concerned, students are prompted to correlate consumerism with the exhaustion of unsustainable resources and with its impact on other peoples and future generations' life (Hicks \& Holden, 2007).

During this two-direction step of action, students are prompted to bring about gradual changes and effect improvements in their personal daily lifestyle, especially in cases where family environment is helpful or susceptible of change (Dislere \& Lice, 2008; Theodoropoulou, Pastrapa, \& Sdrali, 2008)

Collaborating in big groups and with the co-operation of religion and philosophy teachers, they are prompted to reduce excessive consumption and save up money not in order to buy later more products but in order to provide weak social strata with primary necessities or other humanitarian aid. What is mainly expected is students' realization that needs and values of higher rank in A. Maslow's pyramid do not actually need material goods in order to be fulfilled. On the contrary, an energetic, dynamic students' presence and participation in social actions can produce stronger feelings of self-actualization, self-esteem, belonging and safety.

Students' sensitization about environmental issues, such as the climate change, the greenhouse effect, the ozone depletion, the exhaustion of resources and the exploitation of poorer countries' resources and economy by industrialized world (Jensen, 2008), is accomplished through interdisciplinary teaching with the participation of teachers of biology, physics, chemistry, geography and sociology. They examine thoroughly the consequences of environmental change by observing and recording national and international data on environment deterioration, and they are actively involved in local programmes for wastes' recycling, reforestation, wildlife observation, and conservation of flora and fauna through the preservation of their habitats. They contribute in local community information and sensitization by publishing articles in local or school newspapers and by distributing relevant handouts, where a systematic effort is made to highlight the connection between consumer choices and environmental change.

\section{Career Satisfaction of the Graduates of Home Economics and Ecology at Harokopio University of Athens}

\section{Materials and Methods}

A survey was conducted, in order to examine the career satisfaction of the graduates. The statistical frame of the survey was based on the 1998-2000 graduates of home economics and ecology at Harokopio University of Athens. This specified period was selected because Harokopio University was established in 1993, therefore, the first students graduated in 1998. In addition, the survey was interested for alumni/alumnae who had completed all their post graduation endeavours or obligations, such as postgraduate studies or compulsory military service for men, and had settled professionally. The size of the sample used in the study was 120 graduates. Data on the 
characteristics of the graduates were collected through a questionnaire survey. The data collected were analyzed by using descriptive statistics for calculating the means and standard deviations of continuous variables and the frequencies and percentages of discrete variables.

\section{Results of the Survey}

The profile of the Harokopio University's graduates that emerged from this study was that of a woman $(81.7 \%)$ from urban areas (40\%), with an average age 29 years old, non-married (63.3\%) with an average personal monthly income $1,100 €$ which is considered satisfactory.

Ninty seven percent of Home Economic and Ecology Department graduates of the years of 1998-2000 are now (2010) appointed as teachers in different junior high schools of their preference and the rest $3 \%$ have found a job in the private sector, having, however, an occupation related to their studies. Ninety one percent of the graduates are very satisfied or satisfied from their studies, and $97 \%$ are very satisfied from their occupation.

Given the fact that $97 \%$ of the graduates of home economics and ecology at Harokopio University of Athens, were promptly appointed as teachers to Greek high schools, today they are considered to play a major role in the conveyance of the education for consumer citizenship's principles in Greek society, since home economics is the only junior high school subject that promotes and develops consumer awareness in Greek secondary education.

\section{Conclusions}

In the faculty of home economics and ecology at Harokopio University of Athens, student teachers attend special courses on consumer citizenship and are systematically trained to use effectively alternative instructional strategies during the teaching of subject units that refer to consumer citizenship.

Students are prompted to examine how personal choices and attitudes towards consumption have a multileveled impact on others in the present and, also, in the future (Hellstern, 2009). Students look deeper into consumption complicated problems by examining them in the frame of modern economic ethics in order to reveal the degree of personal responsibility for political, economical, social and environmental situations in world places that, at first sight, seem to be quite far-off. Strengthening peoples' solidarity through the projection of "participatory consumerism" constitutes an ambitious objective (McGregor, 2005).

Apparently, for Greek educational system, consumer citizenship education should primarily aim at a radical shift in personal and national values, moral perspectives and ethics, given the fact that a sincere and effective change in behaviour can only be expected where and when people act first as humans and then as consumers.

\section{References}

Carey, L., Shaw, D., \& Shiu, E. (2008). The impact of ethical concerns on family consumer decision-making. International Journal of Consumer Studies, 32(5), 553-560.

Carroll, E. B., \& Reichelt, S. A. (2008). Using current consumer issues to involve students in research. International Journal of Consumer Studies, 32(4), 391-393.

Davis, B., \& Sumara, D. (2006). Complexity and education: Inquiries into learning, teaching and research. Routledge: London.

Dislere, V., \& Lice, I. (2008). Some aspects of consumer citizenship education in Home Economics students' knowledge practice and experience. In: A. Klein, \& V. Thoresen (Eds.) Assessing information as consumer citizens. Proceedings of the 5th international Conference of the Consumer Citizenship Network (Tallinn, Estonia, 2008) (pp. 173-181). Hedmark: Høgskolen i Hedmark-CCN. 
Doyle, D. (Ed.). (2006). Consumer citizenship: Promoting new Responses (Vol. 2): Catalyzing change. Consumer Citizenship Network, Hedmark University College: Hamar.

Frank, B., \& Enkawa, T. (2009). Economic influences on perceived value, quality expectations and customer satisfaction. International Journal of Consumer Studies, 33(1), 72-82.

Gamble, A. (2006). Euro illusion or the reverse? Effects of currency and income on evaluations of prices of consumer products. Journal of Economic Psychology, 27, 531-542.

Georgitsoyanni, E., Koutrouba, K., \& Goussia-Rizou, M. (2003). La contribution de l'économie domestique dans la formation de l'individu via l'école et la famille: l'exemple grec formé sur des modèles suisses. In Société Suisse Pour La Recherché En Education (Ed.), Actes du Congres annuel. Ecole et Famille: Les perspectives dans la difference (pp. 1-6) (CD-ROM). Université de Berne: Berne.

Hanashiro, R., \& Malroutu, L. (2008). Information, values and decision-making that influence the world. In A. Klein, \& V. Thoresen (Eds.), Assessing information as consumer citizens. Proceedings of the 5th International Conference of the Consumer Citizenship Network (Tallinn, Estonia, 2008) (pp. 84-93). Hedmark: Høgskolen i Hedmark-CCN.

Hellstern, G. M. (2009). The impact of globalisation. What is at stake? Economic globalisation and sustainable consumption: A growing disparity. In I. Schrettle, S. Breiting, \& J. Klein (Eds.), Learning sustainable development: Local cases from a global world (pp. 13-20). Graz: Kirchliche Pädagogische Hochschule der Diözese Graz-Sechau-CCN.

Hicks, D., \& Holden, C. (Eds.). (2007). Teaching the global dimension: Key principles and effective practice. Routledge: London.

Jensen, T. (2008). "Political" consumer behaviour and organisation as solidarity and value-sharing with the third world: Trends, possibilities and problems in a governance perspective. In D. Tangen, \& V. Thoresen (Eds.), Building bridges. Proceedings of the 4th international Conference of the CCN (Sofia, Bulgaria, 2007) (pp. 67-71). Hedmark: Høgskolen i Hedmark-CCN.

Koutrouba, K., \& Apostolopoulos, K. (2003). Home economics in ancient Greece and the origins of modern human ecology. Athens: Stamoulis.

McGregor, S. L. T. (2005). The dynamics of shared responsibility: Strategies and initiatives for participatory consumerism. In D. Tangen, \& V. Thoresen (Eds.), Taking responsibility. Proceedings of the 2nd International Conference of the CCN (Bratislava, 2005) (pp. 26-35). Hedmark: Høgskolen i Hedmark-CCN.

McGregor, S. L. T. (2008). Ideological maps of consumer education. International Journal of Consumer Studies, 32(5), 545-552.

Peters, M., Britton, A., \& Blee, H. (Eds.). (2008). Global citizenship education: Philosophy, theory and pedagogy. Rotterdam: Sense Publishers.

Pomeroy, S. B., Burstein, S. M., Donlan, W., \& Roberts, J. T. (2008). A brief history of ancient Greece: Politics, society, and culture. Oxford: Oxford University Press.

Sassatelli, R. (2007). Consumer culture: History, theory and politics. London: Sage.

Theodoropoulou, H., Pastrapa, E., \& Sdrali, D. (2008). Children's involvement in family business and attitudes towards consumers. In A. Klein, \& V. Thoresen (Eds.), Assessing information as consumer citizens. Proceedings of the 5th International Conference of the Consumer Citizenship Network (Tallinn, Estonia, 2008) (pp. 196-205). Hedmark: Høgskolen i Hedmark-CCN.

Williams, T. G. (2002). Social class influences on purchase evaluation criteria. Journal of Consumer Marketing, 19, 249-276. 